\title{
Programa de Educação Ambiental de Itaipu: avanços e desafios de uma experiência de enraizamento da educação ambiental na Bacia Hidrográfica do Paraná 3
}

\section{The Itaipu Environmental Education Program: advances and challenges of an experience of creating the roots of environmental education in Paraná 3}

\author{
Silvana Vitorassi* \\ Miquel F. Oliver Trobat ${ }^{* *}$ \\ Marcos Sorrentino ${ }^{* *}$
}

\begin{abstract}
Resumo: A educação ambiental tem papel fundamental no contexto atual da problemática socioambiental que vive o mundo, como processo potencialmente promotor de mudanças em busca da sustentabilidade. Tais mudanças devem acontecer a partir da participação dos atores sociais que interferem no ambiente, para que eles assumam uma postura atuante na busca por soluções a partir da compreensão da realidade à sua volta, como instrumento de aprendizado e despertando para a ação coletiva. Na Bacia do Paraná 3, desde 2003 vem sendo implementado o Programa de Educação Ambiental do Cultivando Água Boa, da Itaipu Binacional, que, juntamente com diversos parceiros e programas realiza uma educação ambiental participativa e transformadora, em processos de reflexão-ação-reflexão, sensibilizando e formando pessoas e grupos sociais na construção de sociedades sustentáveis. O processo é de mudança de paradigma particularmente para a comunidade acadêmica, uma vez que são incorporadas ao processo de formação de educadores ambientais pessoas até então excluídas do processo formal, fato que possibilita alcançar a capilaridade através da articulação com outros atores sociais, com maior poder de percolação no tecido social, e do encontro dos diversos saberes. Atua além dos bancos da escola, da educação formal, e se amplia para a educação não formal e informal, buscando o seu enraizamento na vida cotidiana das comunidades, num esforço coletivo para a construção de uma nova cultura socioambiental entre aqueles que exercem influência sobre a região. Este trabalho relata essa experiência, trazendo seus aspectos metodológicos, seus avanços e desafios, com a intenção de contribuir para outros programas de educação ambiental.
\end{abstract}

Palavras-chave: Educação Ambiental. Metodologia. Participação. Avaliação.

\begin{abstract}
Environmental Education has a fundamental role in the current context of the socioenvironmental problems that the world faces, as a potential producer of changes in the search for sustainability. Such changes must happen with the participation of the social actors that interfere in the environment, so that they can assume an active posture in search of solutions, starting from the comprehension of the reality around them, as an instrument of learning and awakening to collective action. The enviromental education program 'Cultivating Good Water', in Itaipu Binational has been implemented in the Bacia do Paraná 3 since 2003. This program, jointly with various partners and programs achieves participatory and transformative environmental education through processes of reflection-action-reflection, sensitizing and training people and social groups in the construction of
\end{abstract}

\footnotetext{
* Doutoranda em Educação Ambiental pela Universidade de Ilhas Baleares, Espanha. E-mail: <vitorass@itaipu.gov.br>.

** Professor da Universidade de Ilhas Baleares, Espanha. E-mail: <m.oliver@uib.es>.

*** Doutor em Educação pela Universidade de São Paulo (USP). Professor da USP. E-mail: <marcos.sorrentino@mma.gov.br>.
} 
Programa de Educação Ambiental de Itaipu: avanços e desafios de uma experiência de enraizamento da educação ambiental na Bacia Hidrográfica do Paraná 3

sustainable societies. The process represents a paradigm shift, particularly for the academic community, since they are involved in the process of training environmental educators, people who were previously excluded from the formal process. This is a fact that enables capillarity to be achieved through articulation with other social actors, with greater power for percolation within the social fabric and the encounter of diverse knowledge. The project acts beyond school and formal education, and extends to non-formal and informal education, searching for its roots in the everyday life of communities, in a collective effort towards the construction of a new socio-environmental culture amongst those which exert influence over the region. This study reports this experience, bringing its methodological aspects, its progress and challenges, with the intention of contributing to other environmental education programs.

Keywords: Environmental Education. Methodology. Participation. Evaluation.

\section{Introdução}

Este texto descreve a experiência dos programas de educação ambiental que vêm sendo desenvolvidos na Bacia Hidrográfica do Paraná 3 - BP3, no âmbito do Programa Cultivando Água Boa, da Itaipu Binacional e seus parceiros, analisando os avanços e desafios a fim de contribuir para outros programas de educação ambiental.

O cenário é o de 29 municípios que compõem a área de abrangência da Itaipu
Binacional, maior usina hidrelétrica em geração de energia do mundo (ITAIPU, 2007), que, a partir de 2003, ampliou sua missão. Da missão anterior, passou-se para "Gerar energia elétrica com qualidade, com responsabilidade social e ambiental, impulsionando o desenvolvimento econômico, turístico e tecnológico sustentável no Brasil e no Paraguai” (ITAIPU, 2007, p. 11). A Itaipu Binacional assume assim, como um dos seus principais focos, a responsabilidade socioambiental, destacando o cuidado com a água, eixo orientador das ações.

Figura 1: Foto aérea da Usina Hidrelétrica de Itaipu

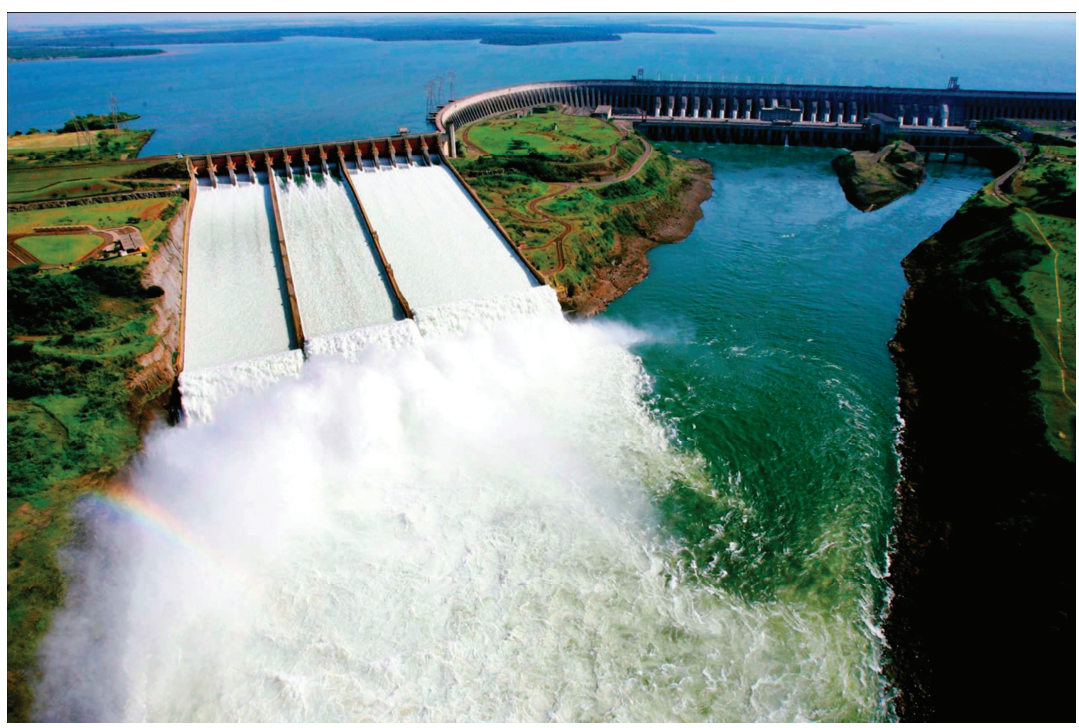

Fonte: Banco de Imagens da Itaipu Binacional.

Olhar de professor, Ponta Grossa, 14(2): 351-367, 2011.

Disponível em <http://www.revistas2.uepg.br/index.php/olhardeprofessor> 
Nesse contexto, Itaipu criou o Programa Cultivando Água Boa - CAB, com o objetivo de estabelecer critérios e condições para orientar as ações socioambientais relacionadas com a conservação dos recursos naturais, centradas na qualidade e quantidade das águas e na qualidade de vida das pessoas.

Trata-se de um movimento que objetiva estimular a sociedade regional a mudar valores no modo de ser, pensar, produzir e consumir, para a busca de um mundo melhor, em especial para o cuidado com a água, com os solos, com a diversidade da vida e das pessoas (ITAIPU, 2008).

Através do CAB, Itaipu adotou como modelo de gestão ambiental a bacia hidrográfica, pois reconhece que os cursos d'água estabelecem a verdadeira territorialidade e comunidade de vida. Amplia assim a atuação dos 16 municípios que fazem margem ao seu Reservatório para os 28 municípios que integram a BP3 e Mundo Novo - MS (somente lindeiro, ou seja, localizado à margem do Reservatório).

O Programa tem como princípios os contidos nos documentos planetários - Tratado de Educação Ambiental para Sociedades Sustentáveis e Responsabilidade Global (princípios também adotados pelo ProNea, 2003) e Carta da Terra -, os quais, segundo Gadotti (2008, p. 9), são “dois importantes e complementares documentos para uma sociedade sustentável”.

A atuação do CAB acontece a partir de parcerias, principalmente locais, para a realização de ações de gestão ambiental que visam à recuperação de passivos ambientais na sua área de abrangência. Tem como símbolo a mandala, que traz como significado o movimento em que Itaipu e parceiros, integrados numa gestão participativa e descentralizada, atuam na BP3.

Figura 2: Imagem da mandala do Programa Cultivando Água Boa

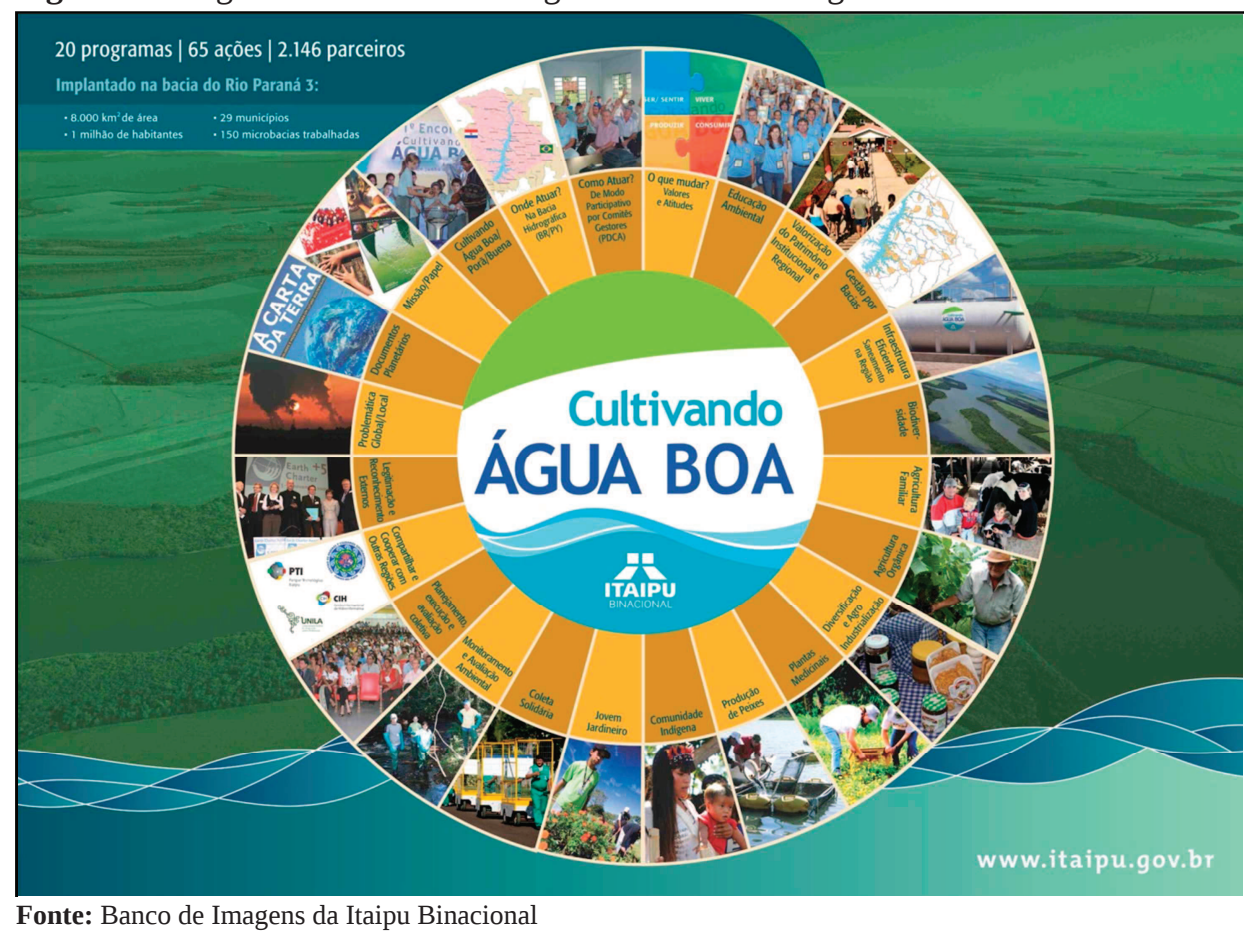

Olhar de professor, Ponta Grossa, 14(2): 351-367, 2011. 
Programa de Educação Ambiental de Itaipu: avanços e desafios de uma experiência de enraizamento da educação ambiental na Bacia Hidrográfica do Paraná 3

Com o foco de Itaipu voltado para a questão da sustentabilidade, a Educação Ambiental adquiriu uma nova dimensão, estando no centro da gestão ambiental a partir da ideia de que as mudanças só acontecem na prática, quando se mudam os valores e os princípios, buscando nos atores sociais sua participação, protagonismo e pertencimento.

Ao mesmo tempo em que o CAB realiza, junto com os parceiros, ações de gestão ambiental para a recuperação dos passivos ambientais, têm sido articuladas e realizadas diversas ações de educação que atuam transversalmente aos seus programas, dentre eles: Plantas Medicinais, Agricultura Orgânica, Coleta Solidária, Jovem Jardineiro e outros.

Sintonizado à missão da empresa, seus princípios e valores, e alinhado à Política Nacional de Educação Ambiental, o Programa de Educação Ambiental de Itaipu atua com ações que estimulam a reflexão dos problemas socioambientais e apoia a comunidade na organização de suas ideias para a busca de soluções dos problemas.

\section{Encaminhamento metodológico e as ações do Programa de Educação Ambiental de Itaipu}

O Programa de Educação Ambiental de Itaipu objetiva a sensibilização e a formação dos diversos atores e grupos sociais para atuarem na construção de sociedades sustentáveis (ITAIPU, 2010). Trata-se de um processo de mudança de paradigma particularmente para a comunidade acadêmica, uma vez que o Programa incorpora ao processo de formação de educadores ambientais pessoas até então excluídas do processo formal na academia. Esse é um dos fatores que possibilita alcançar a capilaridade por promover a articulação com outros atores sociais que têm maior poder de percolação no tecido social, além de promover o encontro dos diversos saberes, que se complementam num saber coletivo que gera outros saberes.

Nesse sentido, além do trabalho com a educação formal, já realizado com muita expressão anteriormente ao CAB, o Programa assume o trabalho não formal e informal, indo dos bancos da escola para a escola da vida.

As ações do Programa de Educação Ambiental de Itaipu estão organizadas em três pilares de atuação, que dialogam entre si. São eles:

1. Educação Ambiental Corporativa;

2. Educação Ambiental nas Estruturas Educadoras de Itaipu: ações realizadas nas unidades do Ecomuseu de Itaipu e do Refúgio Biológico Bela Vista;

3. Educação Ambiental na Bacia do Paraná 3, que abrange a Rede de Educação Ambiental: Linha Ecológica, Agenda 21 do Pedaço e Formação de Educadores Ambientais: FEA.

Em cada uma das ações são desenvolvidas atividades com públicos diversos.

\section{Educação Ambiental Corporativa}

Esta ação atua para "dentro da empresa”, contribuindo na mudança de cultura da organização, por meio da sensibilização e formação das pessoas. Está organizada nas seguintes linhas de atuação:

- Rede Interna de Educadores Ambientais: composta por representantes das áreas de trabalho da empresa, que atuam na sensibilização dos colegas para a reflexão sobre a necessidade de atitudes mais sustentáveis, principalmente das questões: água, consumo sustentável e resíduo. Esses 
colaboradores (mais de 100, conforme Itaipu, 2007, p. 26), de Foz do Iguaçu e Curitiba, atuam de forma voluntária, detectando problemas relacionados à questão socioambiental em suas áreas de atuação, coletando opiniões e impressões dos colegas, disseminando informações, facilitando e editando conjuntamente o cuidado socioambiental. Os trabalhos nos quais a Rede Interna está envolvida incluem:

a) reuniões periódicas de alinhamento, planejamento, avaliação e encaminhamento das ações de EA;

b) visitas técnicas nos espaços onde Itaipu desenvolve trabalhos socioambientais no âmbito interno e externo (Bacia do Paraná 3);

c) atividades de formação;

d) elaboração de materiais informativos/educativos;

e) divulgação do monitoramento da separação de resíduos (Programa de Gerenciamento de Resíduos - Vai e Vem).

- Intervenções Socioambientais Educativas: acontecem em diversos momentos e com atividades diferenciadas. São elas:

a) Nas datas apropriadas, Dia Mundial da Água (22 de março), Dia Mundial do Meio Ambiente (05 de junho) e Dia da Árvore (21 de setembro): visitas às áreas onde atuam os diversos públicos corporativos de Itaipu, incentivando a mudança de atitude necessária à construção da sustentabilidade.

b) Colônia de férias envolvendo filhos dos funcionários da empresa, para que conheçam as ações socioambientais com as quais seus pais se envolvem no ambiente corporativo. São dois dias de atividades educativas de sensibilização, através do contato e vivências nos espaços do Complexo Turístico da Itaipu - Ecomuseu, Refúgio Biológico Bela Vista, Canal da Piracema e Usina de Itaipu - além do Parque Tecnológico de Itaipu. As atividades preveem a participação dos pais, envolvendo assim a família do empregado.

c) Palestras de Integração com empresas terceirizadas, que são intervenções que acontecem em parceria com a área de Segurança Empresarial da Itaipu, com o objetivo de informar e integrar os empregados terceirizados que prestam serviços à Itaipu no ambiente da empresa.

- Rede Corporativa: trata-se de um movimento interno para integrar ações dos vários programas corporativos que visam à mudança de cultura institucional. Dentre esses programas, destacam-se os seguintes: Reviver (de qualidade de vida), Incentivo à Equidade de Gênero, Força Voluntária, Educação Ambiental, Segurança no Trabalho, Conservação de Energia, Desenvolvimento de Recursos Humanos, Universidade Corporativa, Comitê de Responsabilidade Socioambiental. Tais programas estão lotados em várias áreas da empresa e muitos deles estão institucionalizados há vários anos, sendo que os trabalhos se realizam individualmente ou em parcerias esporádicas. Com a Rede Corporativa, passou-se a ter um espaço para diálogos constantes, nos quais se expõem ideias sobre as ações que estão sendo planejadas e buscam-se interfaces de atuação, integrando e potencializando as ações.

Drucker (1975, p. 377) afirma que "para poder fazer o bem, a empresa precisa antes fazer bem”. Portanto, a educação ambiental corporativa é estratégica para uma empresa, principalmente quando sua missão se compromete com a responsabilidade socioambiental, como é o caso da Itaipu Binacional. 
Programa de Educação Ambiental de Itaipu: avanços e desafios de uma experiência de enraizamento da educação ambiental na Bacia Hidrográfica do Paraná 3

\section{Educação Ambiental nas Estruturas Educadoras de Itaipu}

Ações de educação ambiental desenvolvidas nas unidades do Ecomuseu de Itaipu e Refúgio Biológico Bela Vista, utilizando-se esses espaços como estruturas educadoras. Segundo Matarezi (2005, p. 164), "estruturas educadoras são espaços com intencionalidade educadora, ou seja, intenção a propiciar-se aprendizagem aos nossos interlocutores”. A Educação Ambiental nas Estruturas Educadoras de Itaipu trabalha com estudantes, crianças e familiares das comunidades de entorno das unidades, turistas e jovens aprendizes, sensibilizando a partir dos conceitos de sustentabilidade (ITAIPU, 2010).

O Ecomuseu de Itaipu atua a partir dos pilares comunidade, patrimônio e território, em três projetos: Eureka, para escolares; Grupo Comunidade Crescer - GCC, para crianças da comunidade de entorno; e Varanda, para as famílias das crianças que participam do GCC.

Já o Refúgio Biológico Bela Vista atua com o eixo biodiversidade. A educação ambiental é trabalhada no contato direto com a natureza nas seguintes atividades: Amigos do Refúgio (com a comunidade de entorno), Atividades Temáticas (com turistas e estudantes) e Projeto Jovem Jardineiro (jovem aprendiz).

Nessas ações de educação ambiental são atendidas aproximadamente 3.000 pessoas/ano (ITAIPU, 2007, p. 28).

\section{Educação Ambiental na Bacia do Paraná 3}

Esta ação tem como principal objetivo sensibilizar os diversos grupos sociais num processo de educação ambiental reflexivo, crítico e emancipatório. É desenvolvida nos 29 municípios da área de abrangência de Itaipu, com os seguintes públicos: professores, alunos, agricultores, pecuaristas, trabalhadores rurais, pescadores, assentados, índios, catadores de material reciclável, donas de casa, lideranças comunitárias, comerciantes, representantes de instituições parceiras, merendeiras, nutricionistas, representantes de todas as prefeituras municipais da BP3.

A educação ambiental na Bacia do Paraná 3 é constituída por três pilares de atuação:

- Rede de Educação Ambiental Linha Ecológica: resultado da parceria entre Itaipu Binacional, Conselho de Desenvolvimento dos Municípios Lindeiros ao Lago de Itaipu, Prefeituras Municipais da BP3, esta Rede conta com um ônibus equipado para atuação educacional itinerante e com um grupo de educadores ambientais, os "gestores de educação ambiental”, os quais, juntamente com os demais educadores, atuam na região. Os gestores são profissionais das Secretarias Municipais de Educação, Ação Social, Agricultura e Meio Ambiente das 29 prefeituras da BP3 que têm o importante papel de promover a Educação Ambiental no município em toda sua complexidade, transversalmente às outras secretarias municipais, fazendo interface com os demais programas socioambientais desenvolvidos, com vistas à construção participativa do Programa Municipal de Educação Ambiental (ITAIPU, 2008).

O principal foco de atuação desta rede é a educação formal de ensino, atuando com professores, alunos, merendeiras e nutricionistas em processos formativos de agricultura orgânica, plantas medicinais, alimentação saudável, consumo consciente, entre outros. Algumas de suas ações nos últimos anos: 
capacitação de 484 professores municipais de $1^{\mathrm{a}}$ a $4^{\mathrm{a}}$ séries com o tema Consumo Consciente; produção e distribuição dirigida de 135.000 cartilhas Mundo Orgânico; capacitação de grupos teatrais locais e 483 apresentações da peça teatral "A Matita - uma aventura orgânica”, com foco na implementação de hortas orgânicas escolares e familiares; formação continuada para 700 merendeiras e nutricionistas, com o curso Alimentação Saudável e Gestão da Merenda Escolar; I Concurso de Receitas Saudáveis da Bacia do Paraná 3; II Concurso de Receitas Saudáveis da Bacia do Paraná 3 - Edição Orgânica; e 41 oficinas de Ecopedagogia.

Os parceiros envolvidos possibilitam aos gestores a participação em eventos regionais, estaduais, nacionais e internacionais de educação ambiental, nos quais apresentam as ações desenvolvidas na região, conhecem outras experiências, agregam conhecimentos e articulam com outros educadores ambientais.

- Agenda 21 do pedaço: atua principalmente com famílias de agricultores das microbacias que compõem a BP3, onde são trabalhadas ações de recuperação dos passivos ambientais pelo CAB. Por meio das Oficinas de Futuro (inspiradas na metodologia do Instituto Ecoar para Cidadania), a equipe de educação ambiental promove o encontro e o diálogo da comunidade, estimulando e facilitando sua participação nas decisões referentes à gestão daquela microbacia. Essa construção acontece em quatro momentos:

a) Muro das Lamentações: a comunidade expõe suas frustrações, críticas, medos e problemas socioambientais daquela microbacia;

b) Árvore da Esperança: os participantes explicitam o que sonham para o lugar onde vivem e para suas vidas; c) Caminho Adiante: momento em que são definidas metas para as ações corretivas e, por fim, é celebrado um compromisso de cuidado com as águas, o Pacto das Águas;

d) Pacto das Águas: celebração em que a comunidade, lideranças e o poder público selam uma parceria em prol da sustentabilidade (ITAIPU, 2007). No âmbito do Programa Cultivando Água Boa, de 2003 a 2007, foram realizadas 232 oficinas do futuro, envolvendo 17.432 pessoas (ITAIPU, 2007).

Nesta ação, percebe-se a intencionalidade da participação como um meio e não como um fim no processo de gestão por bacia hidrográfica. Essa participação está definida por Tassara (2008, p. 142) como "paradigma que visa o envolvimento das diversas camadas da sociedade nos processos de decisão, relativos ao planejamento e gestão da produção".

- Formação de Educadores Ambientais - FEA: trata-se de um processo de formação de educadores ambientais que foi um marco no enraizamento da educação ambiental no território pesquisado, no que tange principalmente à formação continuada, com base numa educação ambiental crítica, transformadora e emancipatória.

Crítica porque tem como principal enfoque a contextualização dos temas tratados e a importância do diálogo dos saberes: saberes científicos formais, saberes cotidianos, saberes de experiência, saberes tradicionais, etc. Segundo Quintas (2004, p. 132),

ela é crítica na medida em que discute e explicita as contradições do atual modelo de civilização, da relação sociedade-natureza e das relações sociais que ele institui.

Transformadora porque enfatiza a educação como "processo permanente, 
Programa de Educação Ambiental de Itaipu: avanços e desafios de uma experiência de enraizamento da educação ambiental na Bacia Hidrográfica do Paraná 3

cotidiano e coletivo pelo qual agimos e refletimos, transformando a realidade de vida” (LOUREIRO, 2007, p. 81). Segundo Quintas (2004, p. 132),

é uma educação ambiental transformadora porque ao pôr em discussão o caráter do processo civilizatório em curso, acredita na capacidade da humanidade construir outro futuro a partir da construção de um outro presente e assim, instituindo novas relações dos seres humanos entre si e com a natureza.

E emancipatória porque "toma a liberdade como valor fundamental e busca a produção da autonomia dos grupos subalternos, oprimidos e excluídos” (QUINTAS, 2004, p. 132). O sentido que a emancipação adquire na educação ambiental é de um processo educativo que seja capaz de transformar comportamentos, valores, atitudes, estilos de vida e formas de produção que são dominantes na sociedade (LOUREIRO, 2007).

O FEA nasceu de uma parceria da ITAIPU Binacional com os Ministérios do Meio Ambiente e da Educação, que viram no Programa Cultivando Água Boa um terreno fértil para uma iniciativa como esta, de enraizamento da Educação Ambiental num território.

A essa iniciativa somou-se o Parque Nacional do Iguaçu, através da sua escola Parque, unindo a área de abrangência das duas instituições com nove municípios comuns, totalizando 34 municípios a serem trabalhados ${ }^{1}$. Juntaram-se a essas, mais 42 instituições regionais e 34 prefeituras municipais da Bacia do Paraná 3 e entorno do Parque Nacional do Iguaçu, constituindo e

\footnotetext{
${ }^{1}$ Essa parceria se encerrou em 2008 e o Programa continuou com os 29 municípios da área de abrangência de Itaipu.
}

formando o Coletivo Educador da BP3 e do Parque Nacional do Iguaçu, com o papel de atuar na construção, implementação e avaliação constante da proposta de formação de educadores ambientais na região.

Segundo o Órgão Gestor (MMA, 2006, p. 28), o coletivo educador é:

Um grupo de educadoras(es) de várias instituições que atuam no campo da educação ambiental, educação popular, ambientalismo e mobilização social. O Coletivo Educador desenvolve processos formativos sincrônicos de educação ambiental e popular destinados a totalidade da base territorial onde atua, procurando atendê-la de forma permanente e continuada.

O Coletivo Educador desencadeou um processo continuado de formação de educadores/as ambientais no território ilustrado no mapa a seguir. 
Figura 3: Mapa de atuação do Coletivo Educador

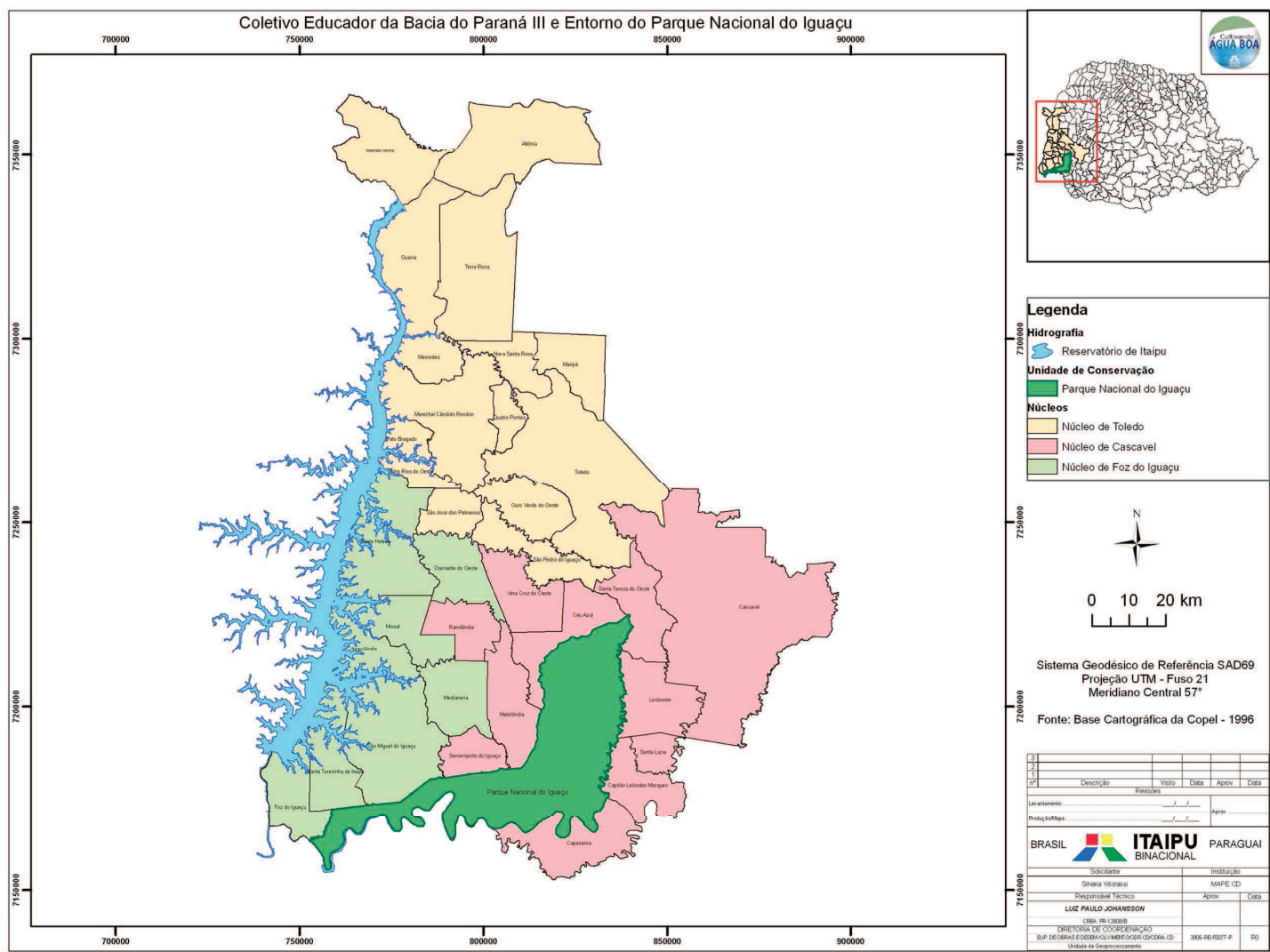

Fonte: Banco de Imagens da Itaipu Binacional.

O processo de formação do FEA expressa os seguintes elementos:

a) A gestão ambiental tem na educação ambiental um de seus elementos fundamentais. As ações técnicas em relação à recuperação dos passivos ambientais e proteção do meio ambiente trazem implícita a necessidade da formação permanente e continuada para a ética do cuidado, o que inclui necessariamente a aprendizagem para o diálogo entre atores sociais e a mediação para casos de conflito ambiental.

b) A participação dos atores sociais que interferem na qualidade do ambiente e da comunidade é fundamental para o êxito na construção de alternativas que visam à sustentabilidade. c) A transversalidade é exercício permanente da educação ambiental, uma vez que os conhecimentos, a consciência e as atitudes adquiridas têm seu pleno significado quando se transformam em ações desenvolvidas com as devidas aptidões e a participação cidadã local e planetária.

d) A aprendizagem da "ética do cuidado” se dá na relação dialógica entre os seres humanos e os demais seres que compõem seu ambiente, do qual fazem parte a democratização e interatividade, a aceitação do pluralismo de ideias e concepções pedagógicas, a valorização das experiências educativas existentes escolares e extra-escolares. 
Programa de Educação Ambiental de Itaipu: avanços e desafios de uma experiência de enraizamento da educação ambiental na Bacia Hidrográfica do Paraná 3

e) A capilaridade como a atuação protagonista em multiplicar os conceitos da educação ambiental para outros atores sociais, estimulando e promovendo momentos de reflexão, diálogos, formação, aproveitando as oportunidades para mobilizar pessoas/ grupos sociais em busca de sociedades sustentáveis.

Seguindo a metodologia de Pesquisa-Ação-Participante - PAP ou, como se convencionou chamar, "Pessoas que Aprendem Participando", o processo FEA tem sua atuação por meio de círculos de diálogos que vão se ampliando. "A cada círculo, mais e mais pessoas são agregadas ao movimento, multiplicando os saberes e cuidados socioambientais (ITAIPU, 2009, p. 23)”, também representados por mandalas de participação multiplicadora.

Orlando Fals Borda (1983, apud VIEZZER, 2005, p. 282) traz o seguinte conceito de PAP:

Trata-se de uma metodologia dentro de um processo vivencial, um processo que inclui simultaneamente educação de adultos, pesquisa científica e ação social ou política, na qual se consideram como fontes de conhecimento, a análise crítica, o diagnóstico de situações e a prática cotidiana.

O grupo PAP1 refere-se aos idealizadores nacionais da proposta, Ministério do Meio Ambiente - MMA e Ministério da Educação - MEC, responsáveis pela elaboração da proposta e repasse desse conhecimento via Oficinas de Trabalhos e impressão de materiais de apoio às iniciativas no país.

Os PAP2, que são os Coletivos Educadores, resultam da aglutinação de esforços e experiências regionais de instituições com atuação regional na área ambiental, cujo trabalho é o de pensar a formação do PAP3, construindo uma metodologia de ensino capaz de dar conta das especificidades locais.

Os PAP3 são educadores/as ambientais formados por meio da proposta e que assumem como desafio o enraizamento da Educação Ambiental nos diversos locais dos municípios. Esse enraizamento é facilitado pela forma de composição dos PAP3, os quais são constituídos por uma multiplicidade de indivíduos que conseguem retratar o tecido social regional. O público a ser trabalhado por esses educadores ambientais, através de proposta de intervenção comunitária, é chamado de PAP4.

Os PAP4 são os diversos grupos sociais presentes nos municípios e que se mobilizam e atuam visando a alcançar políticas públicas que atendam toda a sociedade. Esses grupos se organizam em comunidades de aprendizagem que, de acordo com Brandão (2005, p. 83), são unidades de partilha de vida que proporcionam momentos de aprendizado. Esse aprendizado pode se dar em lugares onde, ao lado do que se faz como motivo principal do grupo (jogar futebol, reunir-se para viver uma experiência religiosa, trabalhar em prol da melhoria da qualidade de vida no bairro, e assim por diante), as pessoas estão também trocando saberes entre elas, estão "se" ensinando e aprendendo.

Vale destacar, no FEA, o processo de capilaridade dos coletivos educadores e o processo de formação como enraizador da educação ambiental num território. Esses processos têm o diálogo como principal tecnologia de construção e realização, capaz de estimular uma nova forma de convívio entre os seres, proporcionando o encontro de saberes, o acolhimento das diferentes visões, histórias de vida, interesses e processos.

O FEA teve a constituição do Coletivo Educador como primeiro grande exercício de um processo considerado 
como participativo, trazendo para o diálogo, para a construção coletiva e para o comprometimento com a sustentabilidade regional diversas instituições com atuação na área socioambiental, no território. Com a constituição do Coletivo Educador, o processo FEA desencadeou as seguintes ações:

a) O Coletivo Educador construiu o “cardápio de aprendizagem”, ou seja, elementos metodológicos e conteúdos identificados como importantes para a região e para o contexto da educação ambiental, bem como as ofertas e demandas que as instituições sugeriram. Segundo Tonso (2005, p. 49),

cardápio de aprendizagem é um elenco de atividades (itens do cardápio) que têm por objetivo proporcionar a formação, no caso, de educadores ambientais da sua região.

Vários temas e assuntos foram levantados, tendo como principais linhas a valorização dos conteúdos de interesse regional e a dinâmica ecológica da região.

b) Numa fase seguinte, realizou-se a seleção dos 300 participantes (PAPs3). A divulgação nos meios de comunicação dos municípios e instituições envolvidas foi realizada pelos PAPs2, que também identificaram e mobilizaram diversos públicos de diversos espaços para que se inscrevessem, exercitando o que chamamos de "olhar distraído". Entre 900 currículos apresentados (cujo roteiro foi elaborado a partir das diretrizes do Programa) e 530 entrevistas coletivas, houve a definição de um grupo de 300 educandos. Tanto na seleção dos currículos como nas entrevistas coletivas houve atuação direta do Coletivo Educador, juntamente com as coordenadoras. As vagas foram divididas entre os municípios, sendo proporcionais ao número de habitantes e garantindo o mínimo de quatro vagas por município, para ter um núcleo mínimo que pudesse dar continuidade ao processo. Os selecionados deveriam atender aos critérios estabelecidos pelo Coletivo Educador: históricos pessoais mais comprometidos com as questões ambientais; atuação e representatividade social; potencial de capilaridade e liderança, considerando sempre a proporcionalidade entre a diversidade sociocultural e o número de habitantes do município, bem como homem/ mulher, rural/urbano, jovem/adulto/idoso etc. Para efetivação de todo esse processo foram realizados seminários, oficinas e reuniões com o Coletivo Educador.

c) O início do processo de formação dos PAPs3 deu-se em 2005, com 298 participantes agrupados em três núcleos de formação/atuação em virtude da proximidade geográfica e número de participantes, ficando assim configurado: núcleo de Cascavel 101 pessoas; núcleo de Foz do Iguaçu - 96 pessoas; e núcleo de Toledo - 101 pessoas. Esse encontro de pessoas com diferentes formações, experiência de vida e atuações é um dos diferenciais do Programa, possibilitando assim o encontro e o diálogo entre os diversos saberes e olhares, a construção de um saber coletivo, diverso e inclusivo. A presença de agricultores e agricultoras, catadores e catadoras de materiais recicláveis, profissionais de comunicação, membros de ONGs e OSCIPs, donas de casa, aposentados, presidentes de associação de moradores e outros enriqueceu o processo de formação, que se deu a partir de três momentos pedagógicos: educação presencial, trabalho em campo (individual e coletivo) e educação difusa. Sua carga horária e principais ações foram estabelecidas na "Trilha do FEA", desenho do caminho a ser percorrido pelos PAPs, transcendendo os espaços do município ou da instituição para um espaço comum e partilhado, da bacia hidrográfica e do entorno do Parque Nacional, como elementos que unem, e não que separam. 
Programa de Educação Ambiental de Itaipu: avanços e desafios de uma experiência de enraizamento da educação ambiental na Bacia Hidrográfica do Paraná 3

Figura 4: Aula Inaugural do FEA

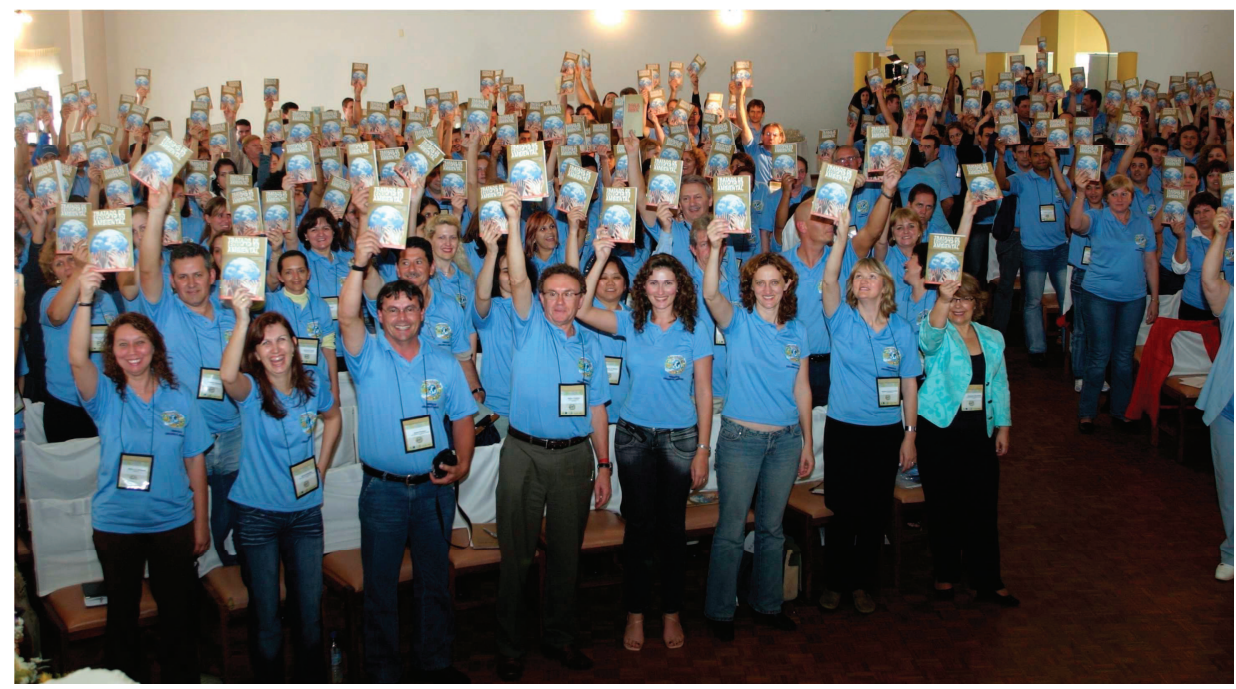

Fonte: Banco de Imagens da Itaipu Binacional.

O cardápio de aprendizagem estabelecido e alinhado às ações socioambientais que já aconteciam na região, principalmente do Programa Cultivando Água Boa e da Escola Parque, estava organizado nos seguintes eixos: - Princípios e valores que orientam a educação ambiental; - Dinâmica ecológica da região; - Intervenção pedagógica.

Havia também o cardápio optativo, que tratava de conteúdos específicos de alguns municípios e/ou instituições, sendo, portanto, possível de ser acessado por quem do grupo tivesse interesse.

O eixo "Dinâmica ecológica da região” se desdobrava em:

- Educação ambiental e unidades de conservação;

- Educação ambiental e gestão de bacias hidrográficas;

- Educação ambiental e saneamento;

- Educação ambiental e agroecologia.

O eixo “Intervenção pedagógica” era o grande desafio da capilaridade, pois dele nasciam as comunidades de aprendizagem ou os PAPs4, sendo o enraizamento propriamente dito da educação ambiental, chegando na base.

As comunidades de aprendizagem se dão a partir da estruturação, do “juntar” de um grupo de pessoas com um objetivo comum num processo de aprendizado mútuo e de reflexão-ação, possibilitando o diálogo, o compartilhamento de experiências, o aprendizado, assim como a realização de intervenções no seu contexto.

Umas das preocupações metodológicas do FEA, desde a seleção dos PAPs4, foi a de pensar na capilaridade dos PAPs3, para que seus PAPs4 tivessem a maior abrangência geográfica e do tecido social possível. Isso se deu graças à diversidade dos participantes. Vale ressaltar que os PAPs2 e 3 trabalharam juntos na constituição das comunidades de aprendizagem.

Diversos foram os símbolos, dinâmicas e rituais nascidos e usados no FEA para trabalhar com a mente, corpo e emoção, trabalho esse que é fundamental em processos de aprendizagem ditos 
transformadores. O FEA teve na simbologia uma grande aliada no despertar do sentimento de pertencimento. Dentre esses símbolos estão: a colcha de retalhos (costurada durante a aula inaugural com pedaços de tecidos representando a participação de cada instituição e de cada pessoa no processo), as músicas, a trilha de formação, os mapas, a bolsa, o crachá, a camiseta. As dinâmicas em círculos, o ritual de cada município em receber o grupo para a formação com suas comidas típicas, as apresentações culturais foram momentos emocionantes que enchiam de sentido os encontros coletivos.

Nos dois primeiros anos de formação (2005-2007), 207 educadores foram capacitados, desencadeando a constituição de 119 comunidades de aprendizagem, totalizando atuação direta com 2.900 pessoas (ITAIPU, 2009, p. 23).

A falta da presença ou de facilitação do PAP3, a mudança de PAP2 do município, a troca de emprego ou endereço dos PAPs foram algumas questões que desmobilizaram comunidades de aprendizagem. Quanto às comunidades que continuaram sua caminhada, podemos resumir seu êxito em algumas características observadas: estruturação de encontros periódicos, apoio das instituições (PAP2), presença do PAP3 como facilitador e planejamento estabelecido.

Dentre as comunidades de aprendizagem constituídas, estão comunidades empresariais, rurais, religiosas, escolares, de associações, de bairro e de mulheres.

De 2008 a 2011, no processo de formação continuada com os PAPs3 trabalhou-se com conteúdos e metodologias/técnicas de intervenção nas comunidades de aprendizagem, abordando-se questões como: intervenção comunitária, oratória, ecopedagogia, entre outras.
Como um desdobramento do Coletivo Educador Regional formou-se o Coletivo Educador Municipal, com o objetivo de articular e realizar ações de forma mais integrada no município, potencializando os diversos recursos.

A continuidade desse processo de formação atualmente acontece pelas seguintes ações:

a) Encontro anual dos PAPs2 e 3 para avaliação e planejamento participativo das atividades, possibilitando no decorrer do processo os ajustes necessários.

b) Encontros bimestrais dos PAPs2, os quais constroem as propostas de atuação conjunta e facilitam os processos de educação ambiental no seu município, a partir da visão regional. Para esse público, a capacitação também é continuada, e teve no último ano a elaboração de projetos e captação de recursos como pontos fortes.

c) Encontros de formação para os PAPs2 e 3.

Atualmente a BP3 conta com 300 PAPs3 com 100 comunidades de aprendizagem atuantes, 29 coletivos educadores municipais, 58 PAPs2 (Coletivo Educador Regional) e aproximadamente 12.000 PAPs 4 .

\section{Resultados e discussão}

A descrição do Programa de Educação Ambiental de Itaipu traz consigo diversos resultados e desafios para análise e reflexão que podem contribuir com outros programas e processos de educação ambiental.

Ao ampliar sua atuação do formal para o não formal, trazendo para o diálogo os diversos atores sociais do seu território de atuação (crianças, jovens, adultos, idosos), o 
Programa em questão assumiu que a educação ambiental não pode ser assunto apenas das escolas, mas deve envolver todos os atores sociais - poluidores e poluídos - e estar presente na sua vivência cotidiana. A partir disso, abre-se para uma educação ambiental inclusiva e muito mais abrangente.

O Programa deixa evidentes duas estratégias que podem ser consideradas como principais, podendo servir como exemplo de promoção da integração, sinergia e comunicação entre áreas e programas que atuam com educação ambiental. A primeira estratégia acontece na Bacia do Paraná 3, e trata-se do trabalho dos "gestores ambientais" que são representantes das 29 prefeituras e que fazem parte do Coletivo Educador PAP2. Esses gestores ambientais realizam o papel de articuladores, integrando as diversas ações vinculadas à educação ambiental no município, dentre elas as do Programa Cultivando Água Boa. A segunda estratégia realiza-se no âmbito interno da empresa, que é a rede corporativa, trazendo para o diálogo os diversos programas corporativos que de alguma forma trabalham aspectos relacionados com a educação ambiental, como, por exemplo, o Programa Reviver, que trabalha com a qualidade de vida dos colaboradores. Busca um alinhamento dessas ações, uma complementaridade, a partir de uma visão sistêmica e integrada da empresa.

É comum conhecermos, em alguns contextos, experiências de ações educativas pontuais ou pulverizadas que desperdiçam não somente energia, mas também recursos financeiros e humanos, tornando-se pontuais e isoladas. Considerando que tanto na empresa como nos municípios as ações de educação ambiental se destinam para o mesmo público e objetivo, é fundamental que estejam conectadas, integradas, com uma visão sistêmica, holística e multidisciplinar otimizando os esforços e recursos, potencializando os resultados e aumentando a relação de confiança com os diversos atores sociais envolvidos.

A confiança é um dos pontos fundamentais que se expressa no processo das Oficinas de Futuro. Quando se inicia um novo trabalho com uma comunidade, muitas vezes as pessoas que ali vivem não acreditam em promessas de melhoria no seu ambiente e na sua vida. No entanto, quando o trabalho se baseia na participação dos atores sociais e no seu protagonismo, possibilitando que os mesmos assumam seu destino, com o apoio de instituições parceiras, cria-se uma relação de confiança mútua e legítima, que depende da transparência das negociações e da continuidade do processo. $\mathrm{O}$ aprendizado coletivo que pode nascer desses momentos de diálogo, reflexão e construção coletiva permanece na vida desses participantes, que vão refletir nas suas atitudes e no cuidado com as pessoas e com o ambiente em que vivem.

Quanto, ainda, à confiança e à credibilidade - que têm especial valor quando se trata de processos baseados nas relações entre os sujeitos que deles participam - podemos destacar no Programa de Educação Ambiental de Itaipu as relações estabelecidas com a comunidade de entorno das suas estruturas educadoras (Ecomuseu e Refúgio Biológico Bela Vista), relações essas que são importantes para que as pessoas se sintam parte dessas estruturas, cuidando e usufruindo do que elas podem oferecer. Nessa mesma linha, a proposta do trabalho com os colaboradores acontecendo nas suas próprias áreas de trabalho, trazendo o sentimento de pertencimento como aliado na sensibilização e colocando a educação ambiental como assunto cotidiano da vida de cada um deles.

O caráter participativo e descentralizado traz para o Programa de 
Educação Ambiental de Itaipu a legitimidade de processos construídos "com” os diversos atores e grupos sociais, refletindo seus anseios e suas especificidades, integrando e valorizando as pessoas, os saberes e os territórios. Nesse sentido, promove o pertencimento e ao mesmo tempo o protagonismo dessas pessoas, além de propiciar a formação que é inerente aos processos de construção coletiva. As pessoas se formam enquanto pensam a formação de outros ou de si mesmas.

O efeito mandala do processo formativo traz uma proposta de capilaridade que, por meio das comunidades de aprendizagem e do perfil dos participantes, chega a diversos "pedaços" do território e percorre todo o tecido social. Assim, atende ao que se espera de uma educação ambiental que se enraíza no cotidiano das pessoas e, num movimento crescente e contínuo, amplia seu alcance em busca de sociedades mais sustentáveis.

Muitos indícios de resultados positivos do Programa de Educação Ambiental de Itaipu foram aqui apresentados. No entanto, faz-se necessário um processo de monitoramento e avaliação estruturado e estabelecido, que possibilite conhecer os resultados e dar visibilidade às mudanças que esse processo promove na vida das pessoas e neste território. Além disso, a avaliação subsidia as tomadas de decisão referentes ao Programa, o alinhamento de conceitos, o redirecionamento das ações, caso necessário, buscando contribuir para o alcance do seu objetivo. A construção desses indicadores deve ser participativa, assim como o processo, e envolver os atores sociais.

Em projetos de educação ambiental, as decisões mais importantes para a avaliação [...] são resultantes da constante análise e reflexão acerca de fatos e percepções, por todos os atores, agentes e demais parceiros que participam do planejamento e da implementação das intervenções. (Arai, Malzyner \& Silveira, 2005, p. 569)

O monitoramento e a avaliação são, portanto, aliados essenciais para um programa de educação ambiental se tornar ainda mais legítimo e enraizador.

\section{Conclusão}

A partir do que foi apresentado, pode-se concluir que:

- A Itaipu Binacional, por meio do Programa Cultivando Água Boa, assumiu a educação ambiental como base de suas ações, acreditando que a verdadeira mudança acontece de dentro para fora e a partir das pessoas, individual e coletivamente.

- O caráter participativo do Programa é essencial para uma educação ambiental transformadora e para despertar o sentimento de pertencimento dos diversos atores sociais do território.

- A participação cidadã local/planetária como assunto de educação ambiental é meta a ser atingida em sua plenitude. Nesse sentido, a metodologia de mandala multiplicadora e agregadora garante a capilaridade nos diversos espaços, permeando todo o tecido social.

- A formação em si, de tantos educadores, já é um fruto expressivo do trabalho de enraizamento da educação ambiental na Bacia Hidrográfica do Paraná 3. A articulação entre os diversos atores e grupos sociais estabeleceu uma grande rede de relações e boas práticas voltadas à sustentabilidade regional.

- Trata-se de um investimento a curto, médio e longo prazo, pois mexe com a cultura de diversas gerações. 
Programa de Educação Ambiental de Itaipu: avanços e desafios de uma experiência de enraizamento da educação ambiental na Bacia Hidrográfica do Paraná 3

- Para o enraizamento da educação ambiental num território, é necessário:

a) investimento em políticas, métodos e estratégias;

b) formação teórica, metodológica e prática de pessoas para atuarem no desenvolvimento de processos participativos;

c) envolvimento dos setores públicos, principalmente no âmbito municipal, para criação de políticas e programas municipais de educação ambiental que garantam a sustentabilidade de ações de educação e gestão ambiental, assim como dos setores privados, que disponibilizam recursos e que na maioria das vezes não são acessados pela região.

- O monitoramento e a avaliação são elementos fundamentais para a continuidade e a sustentabilidade do Programa e devem envolver seus diversos atores sociais.

Assim como uma pedra jogada num lago, o processo de Educação Ambiental vai se propagando e chegando pouco a pouco em todo o território, em todas as pessoas. As dificuldades vão sendo superadas na medida em que se dialoga, constrói caminhos e estratégias e somam-se esforços com as pessoas e instituições envolvidas e comprometidas com a construção de sociedades mais sustentáveis.

\section{Referências}

BRANDÃO, Carlos Rodrigues. Comunidades aprendentes. In: FERRARO Jr., Luiz Antonio (Org.). Encontros e caminhos: formação de educadores/as ambientais e coletivos educadores. Brasília: MMA/DEA, 2005. v.1.

DRUCKER, P. F. Administração: responsabilidades, tarefas e práticas. São Paulo: Pioneira, 1975.
GADOTTI, Moacir. Educar para sustentabilidade. São Paulo: Instituto Paulo Freire, 2008.

ITAIPU BINACIONAL. Caderno cultivando água boa. Foz do Iguaçu: Edição Itaipu Binacional, 2008.

Relatório de sustentabilidade da Itaipu Binacional. Foz do Iguaçu: Edição Itaipu Binacional, 2007.

Itaipu Binacional, 2009. - Foz do Iguaçu: Edição

Texto subsídio para a elaboração do plano diretor de gestão ambiental de Itaipu. Foz do Iguaçu, 2010. (Documento interno).

LOUREIRO, Carlos Frederico B. Emancipação. In: FERRARO Jr., Luiz Antonio (Org.). Encontros e caminhos: formação de educadores/as ambientais e coletivos educadores. Brasília: MMA/DEA, 2007. v.2

MALZYNER, CARLOS; SILVEIRA, Cássio; ARAI, Victor Jun Arai. In: PHILIPPI JR., Arlindo; PELICIONI, Maria Cecília Focesi. Educação ambiental e sustentabilidade. Barueri: Manole, 2005.

MATAREZI, José. Estruturas e espaços educadores. In: FERRARO Jr., Luiz Antonio. Encontros e caminhos: formação de educadores/as ambientais e coletivos educadores. Brasília: MMA/DEA, 2005. v.1

MINISTÉRIO DO MEIO AMBIENTE. Portfólio: Órgão gestor da Política Nacional de Educação Ambiental.Brasília: MMA, 2006.

QUINTAS, José Silva. Educação no processo de gestão ambiental: uma proposta de educação ambiental transformadora e emancipatória. In: LAYRARGUES, Philippe Pomier (Org.). Identidades da educação 
ambiental brasileira. Brasília: Ministério do Meio Ambiente, 2004.

TASSARA, EDA. (Org.). Dicionário socioambiental: ideias, definições e conceitos. São Paulo: FAARTE Editora, 2008.

TONSO, Sandro. Cardápio de Aprendizagem. In: FERRARO, Júnior. Encontros e Caminhos: formação de educadores (as) ambientais e coletivos educadores. Brasília: MMA, 2005.

VIEZZER, Moema. Pesquisa-açãoparticipante (PAP). In: FERRARO Jr. Luiz Antonio (Org.). Encontros e caminhos: formação de educadores/as ambientais e coletivos educadores. Brasília: MMA/DEA, 2005. v.1

Enviado em: 08/10/2011

Aceito em: 29/10/2011 